\title{
Athletes' Emotional Determinants Accordingly Reflected in Their Personal Lives
}

\author{
Heny Setyawati ${ }^{1}$, Nur Haziyanti binti Mohamad Khalid ${ }^{2}$, Didik Rinan Sumekto ${ }^{3}$, Tandiyo \\ Rahayu $^{4}$, Agus Darmawan ${ }^{5}$, Dwi Tiga Putri ${ }^{6}$, Risky Vidiana Sari ${ }^{7}$, Thania Kusumaningtyas ${ }^{8}$, \\ Laksmana Pandu Pratama $^{9}$, Tharisa Dea Florentina ${ }^{10}$ \\ \{henysetyawati@mail.unnes.ac.id ${ }^{1}$, nur.haziyanti@fsskj.upsi.edu.my ${ }^{2}$, didikrinan@unwidha.ac.id $\left.{ }^{3}\right\}$ \\ Universitas Negeri Semarang, Semarang, Indonesia ${ }^{1}$ \\ Universiti Pendidikan Sultan Idris, Malaysia ${ }^{2}$ \\ Universitas Widya Dharma, Klaten, Indonesia ${ }^{3}$
}

\begin{abstract}
This study aims at examining athletes' emotional determinant as reflected in their personal lives. 278 voluntarily elite athletes contributed to the database, they were individual-athletes and team-athletes of 28 sport branches. Data were collected from selfrated questionnaire towards athletes' emotional determinants using a 5-point Likert scale. Data analysis used the SPSS for calculating athletes' emotional determinants. The results showed that self-expression, self-control, and problem-solving for individual- and teamathletes were significantly correlated with each other. Another finding confirmed that the highest value of domination of elite athletes' emotional determinants on self-expression dealt with the lowest value of self-control. The domination of these three determinants was consequently partial positive and negative significance with $\mathrm{p}<0.01$ level for 2-tailed prediction linking to Spearman's Rho coefficients. Elite athletes' emotion deals with intra-and inter-individual contexts that constitute with the multiple positive, negative, and supportive reactions. However, elite athletes' emotion conditionally influences their individual competence inventories.
\end{abstract}

Keywords: self-expression, self-control, problem-solving, emotion consistency.

\section{Introduction}

Throughout the most recent twenty years, sport psychology research has added to the exhibition of elite athletes through the usage and practice of accessibly psychological strategies and methods, for example, unwinding, objective setting, mental practice, perception and self-talk. Generally, the mental strategies have been all the more broadly considered by analyzing mental aptitudes got from different character characteristics and mental demeanors of elite athletes [1], since in the advanced globalization, the upgraded performance requests pressure that will be available all around, and one of us can get away from the day-by-day life stresses. Unpleasant life occasions and every day life stresses have both pernicious and aggregate consequences for human body [2].

The group of emotional capabilities is tied in with utilizing sentiments and feelings to manage your musings and conduct. It implies getting in the temperament and utilizing sentiments and feelings to encourage thinking and dynamic. The capacity to utilize feelings can assist you with distinguishing various situations and give you an alternate and upgraded point of view on issues in work and family life. It will help you see the world contrastingly 
and acknowledge others' perspectives towards what others are feeling and spotlight on that which is significant when emotions are solid [1]. An away from of the elite athletes in zeroing in on close to home exertion and personal growth, building up an adoration for sports, just as attempting to improve specialized strategic viewpoints will identify with their sports to improve execution, key component in self-inspiration [3].

When elite athletes can perceive their passionate states viably, they must have the option to control those equivalent feelings. For this situation, elite athletes show their capacity of creating and being intellectually extreme, regardless of the conditions occur. Elite athletes need to keep up a balance of feelings that adjusts the two highs and lows on the off chance that they would like to create consistency in their art. This implies that there are not dwelling on the two disappointments and victories. Elite athletes' enthusiastic state additionally comes off on teammates which make their guideline of feelings much more significant as it can influence the general either team's performance or individual lives. This equivalent attitude will be persisted into the working zones. In any case, it is fundamental to keep athletes' levelheadedness in the most high-pressure circumstances. By managing athletes' emotions, they can resist the urge to panic and zero in on the errand that should be cultivated [4].

Elite athletes' emotions are well-springs of information that alongside the normal data, can help them settle on very much educated choices. These additionally covers the capacity to oversee elite athletes' sentiments and emotions in pressurized and distressing circumstances to support their both performance and individual lives [1]. Elite athletes' bodily and mind emotions contain verse of every experience, mutual understanding, and relationships in their individual lives. They will comprise the feeling of who they are and stimulate the systems as energy. As the emotion consistency increased, the form of the energy within the individual will be switched, resulting in changes in the individual athletes' working experience, lives, and relationships. However, managing emotions consistency effectively convey administering the fruitless behaviors that do not seem to be beneficial to the elite athletes [5].

Some studies regarding the emotion consistency noted that self-esteem positively predicted self-determined motivation, whereas anxiety predicted it negatively and selfdetermined motivation positively also predicted resilience. This condition helped to better understand how different behavioral, emotional, and social aspects belonging to the athletes interrelated with the others [6]. [7] believed that athletes who practiced collective sports with the physical contact were the ones, who was better in handling their emotions. Further, understanding athletes' emotions helped predict how they reacted to different situations. The situation was about developing a map of how emotions worked, how athletes' emotions could lead to another and result in a particular emotional state. This covered understanding the warning signs of emotional states, such as restlessness, apprehension and anger. Possession of an emotional map enabled athletes to deal more effectively with the ups and downs in lifestyle [1]. Meanwhile, [8] showed that elite athletes' key factors on emotions consistency might involve their psychological strikes of unjustness, overtraining and burnout, serious public and media covers; and overseeing progressing serious weights to perform in their individual lives. On the other hand, individually specific psychological differences among elite athletes might rise to better tolerance of physiological arousal [9].

Along consideration with elite athletes' emotion consistency is accordingly depicted in athletes' individual lives. The purpose of this research analyses three embedded determinants of elite athletes' emotion in terms of self-expression, self-control, and problem-solving through the descriptive statistics analyses, which is empirically based on elite athletes' perception of using the self-rated questionnaire. The questionnaire reveals elite athletes' individual lives that correspond with the outreach of their professional careers. Pointedly, this 
research aims at examining the oversight of athletes' emotion consistency as depicted in their individual lives.

\section{Method}

Respondents were elite athletes listed from 28 category of sports both individual and team sports, namely: of wushu $(n=19)$, taekwondo $(n=16)$, hockey $(n=22)$, baseball $(n=18)$, softball $(n=13)$, boxing $(n=2)$, roller-skate $(n=11)$, shooting $(n=9)$, weightlifting $(n=7)$, archery $(n=12)$, gliding $(n=8)$, basketball $(n=12)$, motor-cross $(n=7)$, beach volleyball $(n$ $=3)$, karate $(n=9)$, court tennis $(n=5)$, full-body contact $(n=12)$, badminton $(n=8)$, sambo $(n=3)$, diving $(n=8)$, paragliding $(n=8)$, handball $(n=28)$, kempo $(n=10)$, pencak silat $(n$ $=8)$, aeromodelling $(n=4)$, judo $(n=11)$, hang-gliding $(n=3)$, and athletics $(n=2)$. These elite athletes were officially programmed at athletes' training center program, Indonesian National Sport Committee (KONI). The respondents voluntarily involved in this research were 278 elite athletes. They were listed to the database, namely: $18.3 \%(\mathrm{n}=51)$ individual-athletes and $81.7 \%(\mathrm{n}=227)$ team-athletes. Athletes' age ranged from 14 to 35 years with a mean of 24.5 and standard deviation of 14.849 (Mage $=24.5$; SD $=14.849$ ) when they completely fulfilled the questionnaires.

Data were collected from those elite athletes' self-rated questionnaire towards their emotion consistency perception using a 5-point Likert scale regarding three determinantsself-expression, self-control, and problem-solving. The rubric indicated that 5-very consistent, 4-consistent, 3-moderate, 2-less moderate, and 1-uninfluenced. However, these three determinants had fulfilled the research instrument that was previously tested towards other 47 elite athletes in athletes' training center program by means of Cronbach's alpha reliability coefficients. The results ranked in between .535 to .703 with the significance level at $\mathrm{p}<.30$. The Cronbach's alpha $(\alpha)$ for self-expression was .703, self-control was .535, and problemsolving was .562.

Data analysis had been undertaken from applying the IBM SPSS 25.0. In association with the statistics analyses, the descriptive and frequency statistics of athletes' inter-group perception were used to examine both individual- and team-athletes' emotion consistency. Subsequently, the correlations among three determinants-self-expression, self-control, and problem-solving were carried out using Spearman's rho with the significance level at $\mathrm{p}<.01$.

\section{Result and Discussion}

This descriptive statistics and cross-sectional study relied on two hundred seventy-eight $(n=278)$ elite athletes that were undertaken from the category of individual- and teamathletes (52 or $18.3 \%$ individual athletes and 227 or $81.7 \%$ team-athletes), whose age laid on 14 to 35 years $($ Mage $=24.5$; SD $=14.849)$. Firstly, regarding the dominance of individualathletes' self-expression as depicted in their individual lives, it was shown that elite athletes answered their self-expression was less moderate ( 9 or $17.6 \%$ ), 23 or $45.1 \%$ was moderate, 14 or $27.5 \%$ was consistent, and 5 or $9.8 \%$ was very consistent (Table 1). Elite athletes' selfexpression also addressed the mean was 3.29 and standard deviation was $.879(\mathrm{M}=3.29$; SD $=.879 ; \mathrm{n}=51)$. The category of elite athletes' self-expression was moderate with $45.1 \%$ and ranked into the first category based on individual-athletes' emotion consistency (Fig. 1). 
Table 1. Frequencies of individual-athletes' self-expression.

\begin{tabular}{lrrrr}
\hline Likert's Scale & Frequency & Percent & Valid Percent & Cumulative Percent \\
\hline 2.00 (Less moderate) & 9 & 17.6 & 17.6 & 17.6 \\
3.00 (Moderate) & 23 & 45.1 & 45.1 & 62.7 \\
4.00 (Consistent) & 14 & 27.5 & 27.5 & 90.2 \\
5.00 (Very consistent) & 5 & 9.8 & 9.8 & 100.0 \\
$\quad$ Total & $\mathbf{5 1}$ & $\mathbf{1 0 0 . 0}$ & $\mathbf{1 0 0 . 0}$ & \\
\hline
\end{tabular}

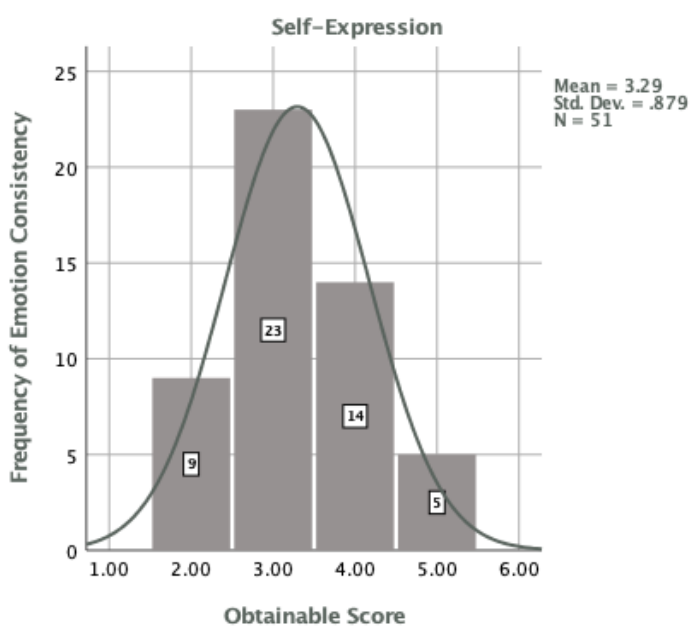

Fig. 1. Histogram of individual-athletes' self-expression

Secondly, the dominance of individual-athletes' self-control as depicted in their individual lives showed less moderate. Completely, it was displayed that elite athletes answered their self-control in the following category: $13(25.5 \%)$ was uninfluenced, $18(35.3 \%)$ was less moderate, $14(27.5 \%)$ was moderate, $5(9.8 \%)$ was consistent, and 1 (2.0\%) was very consistent (Table 2). Elite athletes' self-control also confirmed the mean was 2.27 and standard deviation was $1.021(M=2.27 ; S D=1.021 ; n=51)$. This category ranked into the third level regarding individual-athletes' emotion consistency confirming their individual lives (Fig. 2).

Table 2. Frequencies of individual-athletes' self-control

\begin{tabular}{lcrrr}
\hline Likert's Scale & Frequency & Percent & Valid Percent & Cumulative Percent \\
\hline 1.00 (Uninfluenced) & 13 & 25.5 & 25.5 & 25.5 \\
2.00 (Less moderate) & 18 & 35.3 & 35.3 & 60.8 \\
3.00 (Moderate) & 14 & 27.5 & 27.5 & 88.2 \\
4.00 (Consistent) & 5 & 9.8 & 9.8 & 98.0 \\
5.00 (Very consistent) & 1 & 2.0 & 2.0 & 100.0 \\
\multicolumn{1}{c}{ Total } & $\mathbf{5 1}$ & $\mathbf{1 0 0 . 0}$ & $\mathbf{1 0 0 . 0}$ & \\
\hline
\end{tabular}




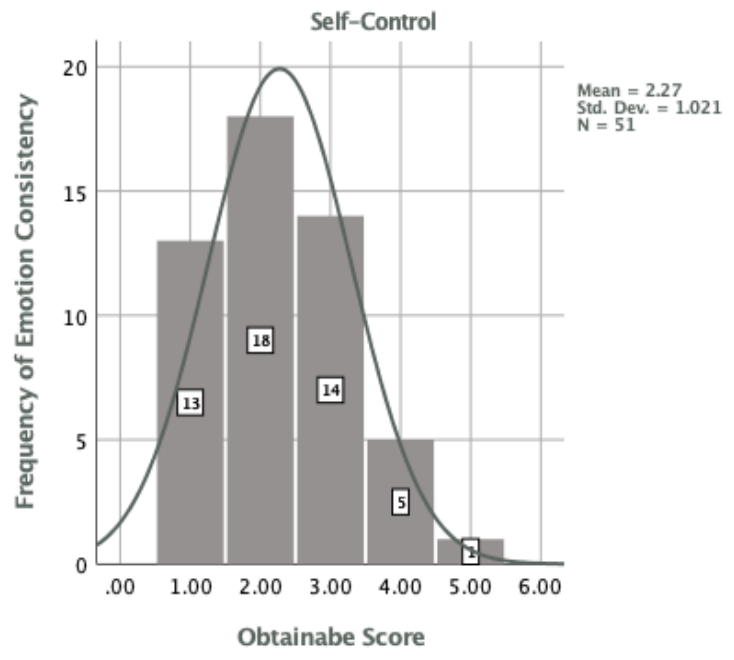

Fig. 2. Histogram of individual-athletes' self-control.

Table 3. Frequencies of individual-athletes' problem-solving.

\begin{tabular}{lcrrr}
\hline Likert's Scale & Frequency & Percent & Valid Percent & Cumulative Percent \\
\hline 1.00 (Uninfluenced) & 3 & 5.9 & 5.9 & 5.9 \\
2.00 (Less moderate) & 13 & 25.5 & 25.5 & 31.4 \\
3.00 (Moderate) & 21 & 41.2 & 41.2 & 72.5 \\
4.00 (Consistent) & 9 & 17.6 & 17.6 & 90.2 \\
5.00 (Very consistent) & 5 & 9.8 & 9.8 & 100.0 \\
\multicolumn{1}{c}{ Total } & $\mathbf{5 1}$ & $\mathbf{1 0 0 . 0}$ & $\mathbf{1 0 0 . 0}$ & \\
\hline
\end{tabular}

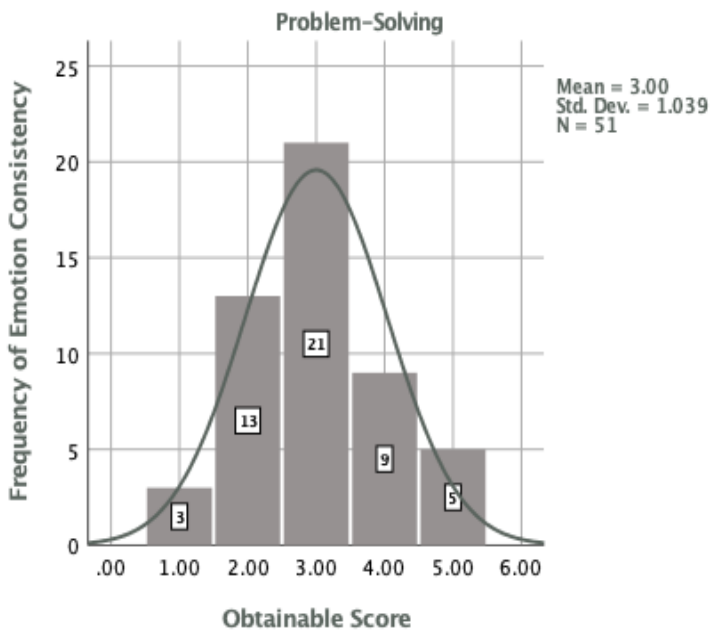

Fig. 3. Histogram of individual-athletes' problem-solving 
Thirdly, the dominance of individual-athletes' problem-solving as depicted in their individual lives indicated moderate. The overall category of elite athletes' problem-solving was accordingly recorded, as follows: 3 (5.9\%) was uninfluenced, 13 (25.5\%) was less moderate, $21(41.2 \%)$ was moderate, $9(17.6 \%)$ was consistent, and $5(9.8 \%)$ was very consistent (Table 3). Elite athletes' problem-solving notably verified the mean was 3.00 and standard deviation was $1.039(M=3.00 ; S D=1.039 ; n=51)$. This category ranked into the second level considering individual-athletes' emotion consistency among their individual lives (Fig. 3).

On the other hand, 227 or $81.7 \%$ team-athletes correspondingly conveyed their dominance of team-athletes' emotion consistency determination as depicted in their individual lives with less moderate and moderate category. In this determinant, the categories of elite athletes' self-expression were consequently relied on moderate category with the following results: $1(.4 \%)$ was uninfluenced, $53(23.3 \%)$ was less moderate, $97(42.7 \%)$ was moderate, $58(25.6 \%)$ was consistent, and $18(7.9 \%)$ was very consistent (Table 4). Elite athletes' selfexpression confidently recorded the mean was 3.17 and standard deviation was $.893(\mathrm{M}=$ 3.17; $\mathrm{SD}=.893 ; \mathrm{n}=227$ ). This category ranked into the first level figuring team-athletes' emotion consistency regarding their individual lives (Fig. 4).

Table 4. Frequencies of team-athletes' self-expression.

\begin{tabular}{lcrrr}
\hline Likert's Scale & Frequency & Percent & Valid Percent & Cumulative Percent \\
\hline 1.00 (Uninfluenced) & 1 & .4 & .4 & .4 \\
2.00 (Less moderate) & 53 & 23.3 & 23.3 & 23.8 \\
3.00 (Moderate) & 97 & 42.7 & 42.7 & 6.5 \\
4.00 (Consistent) & 58 & 25.6 & 25.6 & 92.1 \\
5.00 (Very Consistent) & 18 & 7.9 & 7.9 & 100.0 \\
$\quad$ Total & $\mathbf{2 2 7}$ & $\mathbf{1 0 0 . 0}$ & $\mathbf{1 0 0 . 0}$ & \\
\hline
\end{tabular}

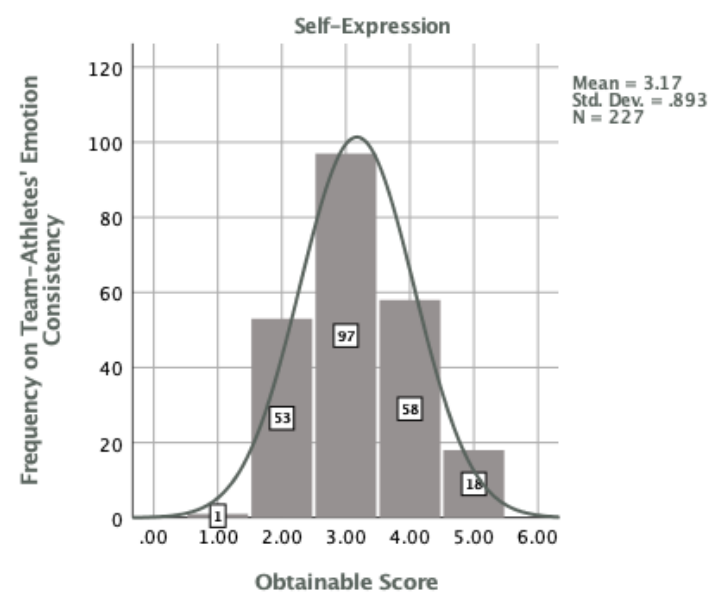

Fig. 4. Histogram of team-athletes' self-expression. 
Another dominance of team-athletes' emotion consistency complied with elite athletes' self-control who definitely corresponded with the results of less moderate category with the descriptions, as follows: $50(22.0 \%)$ was uninfluenced, $80(35.2 \%)$ was less moderate, 72 $(31.7 \%)$ was moderate, 20 (8.8\%) was consistent, and $5(2.2 \%)$ was very consistent (Table 5). Elite athletes' self-control empirically reported the mean was 2.34 and standard deviation was $.989(M=2.34 ; S D=.989 ; n=227)$. This category ranked into the lowest level among three determinants that figured out team-athletes' emotion consistency in their individual lives (Fig. 5).

Table 5. Frequencies of team-athletes' self-control.

\begin{tabular}{lcrrr}
\hline Likert's Scale & Frequency & Percent & Valid Percent & Cumulative Percent \\
\hline 1.00 (Uninfluenced) & 50 & 22.0 & 22.0 & 22.0 \\
2.00 (Less moderate) & 80 & 35.2 & 35.2 & 57.3 \\
3.00 (Moderate) & 72 & 31.7 & 31.7 & 89.0 \\
4.00 (consistent) & 20 & 8.8 & 8.8 & 97.8 \\
5.00 (Very consistent) & 5 & 2.2 & 2.2 & 100.0 \\
\multicolumn{1}{c}{ Total } & $\mathbf{2 2 7}$ & $\mathbf{1 0 0 . 0}$ & $\mathbf{1 0 0 . 0}$ & \\
\hline
\end{tabular}

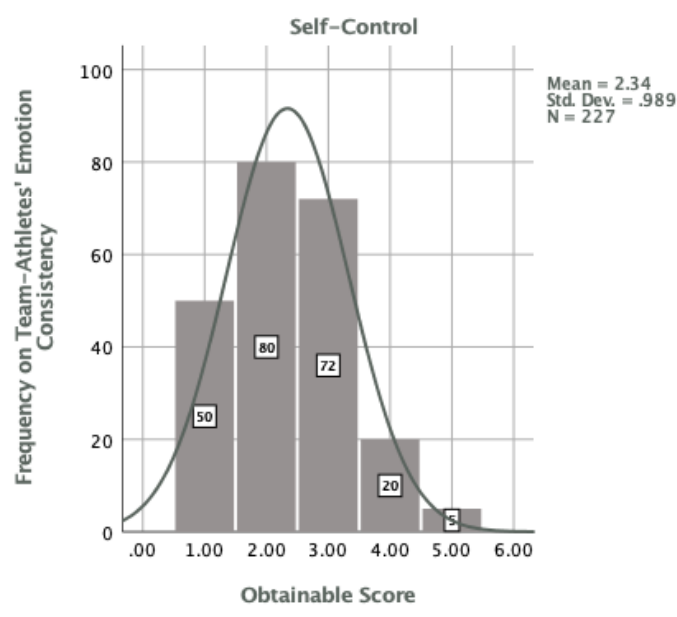

Fig. 5. Histogram of team-athletes' self-control

Lastly, the dominance of team-athletes' emotion consistency established elite athletes' problem-solving who variably confirmed with the results of moderate category and described with the following results: $12(5.3 \%)$ was uninfluenced, $58(25.6 \%)$ was less moderate, 67 $(29.5 \%)$ was moderate, $64(28.2 \%)$ was consistent, and $26(11.5 \%)$ was very consistent (Table 6). Elite athletes' problem-solving evidently recorded the mean was 3.15 and standard deviation was $1.091(M=3.15 ; S D=1.091 ; n=227)$. This category placed the second category among other two determinants that determined team-athletes' emotion consistency in their individual lives (Fig. 6). 
Table 6. Frequencies of team-athletes' problem-solving.

\begin{tabular}{lcrrr}
\hline Likert's Scale & Frequency & Percent & Valid Percent & Cumulative Percent \\
\hline 1.00 (Uninfluenced) & 12 & 5.3 & 5.3 & 5.3 \\
2.00 (Less moderate) & 58 & 25.6 & 25.6 & 30.8 \\
3.00 (Moderate) & 67 & 29.5 & 29.5 & 60.4 \\
4.00 (consistent) & 64 & 28.2 & 28.2 & 88.5 \\
5.00 (Very consistent) & 26 & 11.5 & 11.5 & 100.0 \\
\multicolumn{1}{c}{ Total } & $\mathbf{2 2 7}$ & $\mathbf{1 0 0 . 0}$ & $\mathbf{1 0 0 . 0}$ & \\
\hline
\end{tabular}

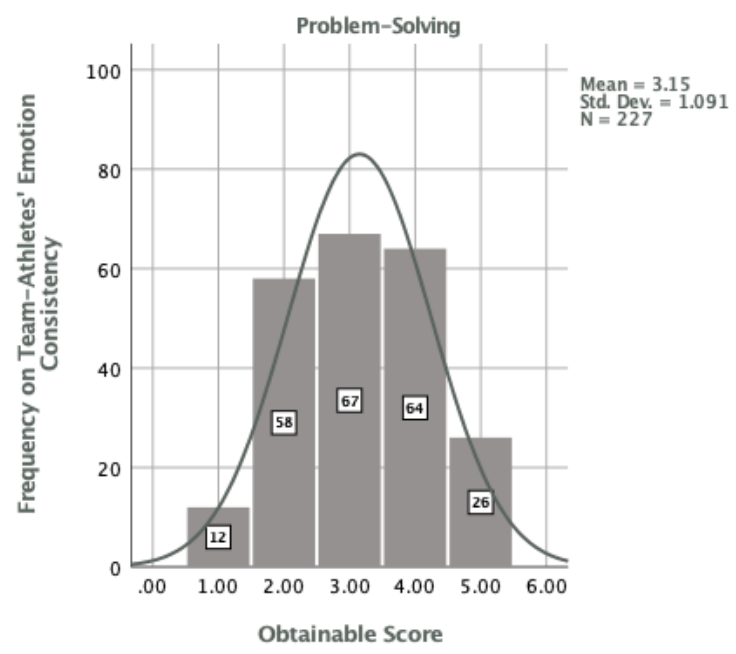

Fig. 6. Histogram of team-athletes' problem-solving.

The descriptive statistics of both individual- and team-athletes' emotion consistency established the depicted determinants of athletes' individual lives, such as self-expression, self-control, and problem-solving. In this respect, two hundred seventy-eight $(n=278)$ elite athletes from the sports category engaged in the questionnaire-based research. This descriptive analysis was set forth in a 5-point-Likert scale to measure elite athletes' emotion consistency which depicted their individual lives. The results of elite athletes' descriptive statistics were shown in Table 7 determining individual-athletes' self-expression $(M=3.29 ; S D=.878)$, selfcontrol $(M=2.27 ; S D=1.021)$, and problem-solving $(M=3.00 ; S D=1.039)$, whilst teamathletes' self-expression $(M=3.17 ; S D=.893)$, self-control $(M=2.33 ; S D=.988)$, and problem-solving $(M=3.14 ; S D=1.090)$. The statistics for the individual-athletes on selfexpression' skewness was .289; kurtosis was -.492, self-control's skewness was .469; kurtosis was -.492, and problem-solving's skewness was .223; kurtosis was -.492, whereas the individual-athletes on self-expression' skewness was .294; kurtosis was -.537, self-control's skewness was .385; kurtosis was -.289, and problem-solving's skewness was -.012; kurtosis was -.807. Both individual- and team-athletes' determinants of elite athletes' emotion consistency were inconsiderable for 278 elite athletes' individual lives. Of the skewness and 
kurtosis shown in the determinants of elite athletes' emotion consistency, the data were normally distributed. However, either individual-athletes $(M=2.27)$ or team-athletes' $(M=$ 2.33) emotion consistency gained the lowest mean in self-control.

Table 7. Descriptive statistics of individual- and team-athletes' emotional determinants.

\begin{tabular}{c} 
Category of Individual- and Team-Athletes \\
\hline Individual-Athletes $=\mathbf{1 8 . 3 \%}(\boldsymbol{n}=\mathbf{5 1})$ \\
Self-Expression $(M=3.29 ; S D=.878 ;$ Skewness $=.289 ;$ Kurtosis $=-.492)$ \\
Self-Control $(M=2.27 ; S D=1.021 ;$ Skewness $=.469 ;$ Kurtosis $=-.492)$ \\
Problem-Solving $(M=3.00 ; S D=1.039 ;$ Skewness $=.223 ;$ Kurtosis $=-.492)$ \\
Team-Athletes $=\mathbf{8 1 . 7 \%}(\boldsymbol{n}=\mathbf{2 2 7 \%})$ \\
Self-Expression $(M=3.17 ; S D=.893 ;$ Skewness $=.294 ;$ Kurtosis $=-.537)$ \\
Self-Control $(M=2.33 ; S D=.988 ;$ Skewness $=.385$ Kurtosis $=-.289)$ \\
Problem-Solving $(M=3.14 ; S D=1.090 ;$ Skewness $=-.012 ;$ Kurtosis $=-.807)$ \\
\hline
\end{tabular}

Additionally, the analysis constituted with three determinants dominating elite athletes' emotion consistency. The significant correlations were $r=1.000, n=278, p<0.01$. The highest value of domination of elite athletes' emotion consistency on self-expression dealt with the lowest value of self-control. Notwithstanding, the domination of these three determinants was consequently partial positive and negative significance with $\mathrm{p}<0.01$ level for 2-tailed prediction. Table 8 showed the Spearman's Rho coefficients in the following ranks: 1.000 , $.191 * *,-.203 * *$, and $-.239 * *$.

Table 8. Spearman's Rho correlations of both individual- and team-athletes' emotional determinants.

\begin{tabular}{|c|c|c|c|c|c|}
\hline & & & $\begin{array}{r}\text { Self- } \\
\text { Expression }\end{array}$ & $\begin{array}{r}\text { Self- } \\
\text { Control }\end{array}$ & $\begin{array}{r}\text { Problem- } \\
\text { Solving }\end{array}$ \\
\hline \multirow{9}{*}{$\begin{array}{l}\text { Spearman's } \\
\text { Rho }\end{array}$} & \multirow{3}{*}{$\begin{array}{r}\text { Self- } \\
\text { Expression }\end{array}$} & Correlation & 1.000 & $-.203^{* *}$ & $.191 * *$ \\
\hline & & $\begin{array}{r}\text { Coefficient } \\
\text { Sig. (2-tailed) }\end{array}$ & - & .001 & .001 \\
\hline & & $\mathrm{N}$ & 278 & 278 & 278 \\
\hline & \multirow[t]{3}{*}{ Self-Control } & $\begin{array}{l}\text { Correlation } \\
\text { Coefficient }\end{array}$ & $-.203 * *$ & 1.000 & $-.239 * *$ \\
\hline & & Sig. (2-tailed) & .001 & - & .000 \\
\hline & & $\mathrm{N}$ & 278 & 278 & 278 \\
\hline & \multirow[t]{3}{*}{$\begin{array}{r}\text { Problem- } \\
\text { Solving }\end{array}$} & $\begin{array}{l}\text { Correlation } \\
\text { Coefficient }\end{array}$ & .191 & $-.239 * *$ & 1.000 \\
\hline & & Sig. (2-tailed) & .001 & .000 & - \\
\hline & & $\mathrm{N}$ & 278 & 278 & 278 \\
\hline
\end{tabular}


This research performed with the sample of 278 elite athletes, regarding the emotion consistency in athletes' daily lives involving their self-expression, self-control, and problemsolving. These determinants were equivalent with those highlighted by [10] and [11] that being uncontrollable emotion utilization to be the lowest rated matter that influenced elite athletes' individual lives daily. Conversely, [12] pointed out that higher values of emotion perception in team-athletes corresponded with the lower figures to athlete's self-emotional management. However, when connected to the emotion consistency, elite athletes' egooriented climate and its categories were verifiable, relating to a significant orientation towards these determinants. The influential matters addressed elite athletes' sports category as their professional background and individual lives that corresponded with their different social variables [13]. As regards relationships between elite athletes' emotion consistency and their individual lives of both individual- and team-athletes, the descriptive statistics results had found the significant contribution, although there is a tendency towards slightly lower mean elite athletes' self-control. In this regard diverse exploration concentrates with opposing outcomes are discovered, corresponding information acquired with those found in examination by [14]. Notwithstanding, they differed from the data found by [15], [16], and [17], in which the higher levels of emotional consistency might influence and implicate athletes' feelings in their individual lives, in terms of the designated determinants effectively.

On the other hand, sport psychology had evolved and advanced to the point where its application had become a key component in the peak performance of elite athletes in many fields and at many levels of competitive activity [5]. Hence, three kind of determinants used to assess elite athletes' emotion consistency in this research influenced the data, since both the individual-athletes and team-athletes enabled them to prove and maintain their emotions in the daily lives effectively. Results could explain the empirical situation where three determinants, namely: self-expression, self-control, and problem-solving might closely support to elite athletes' emotion consistency engagement. Firstly, this discussion addressed elite athletes' self-talk that was motivationally used to improve attention and assuredness, and reduce anxiety among elite athletes. As part of self-expression, self-talk relied on the positive things that were immediately followed by the negative things which could enroll a substantial matter in assisting elite athlete to stay focused on current situation and strategies, as well as to avoid the bewilderment that hampered achievements [18]. Self-expression skills was a central to the recovery process, specially regarding to the process of identifying elite athletes' current emotions when undertaking actions. Ultimately, managing self-expression skills benefited elite athletes' physical and mental recovery and held positive effects on long-term health, well-being, and performance [19].

Secondly, individual-athletes required a high level of performance that would be more effective than team-athletes to perform elite athletes' self-control and needed to convey sufficient support and feedback to obtain the better benefits [20]. Self-control characterized chronic adaptation to positive social interaction with the others. In such important and relational contexts, the affective trust strengthened the effect of appreciation on elite athletes' self-esteem over the time to discover new boundary conditions [21]. Self-control was frequently confirmed to create applicable, effortful recovery activities. That was, elite athletes might hold to wield their self-control to handle activities, especially when they were exhausted, stressed, or in negative moods [19]. The self-control assumed that all actions, such as emotion regulation, and persistence were empowered by the global metaphorical strengths that had small capacity. This became temporarily decreased soon after a major self-control acts, which alternatively could impair elite athletes' performance. Currently, the assumptions of self-control also had been reflected and examined by the field of sports and exercise 
psychology [22]. In addition, self-control was associated with time spent on several daily activities. Self-control helped elite athletes stand for the tracks. It might also increase elite athletes' perceivable performance by assisting them overcome barriers, which made them more comfortable [23].

Thirdly, problem solving in in both individual- and team-athletes required problem identification, intervention, and sustainable assessments. Highlighting the sequence of complex cognitive processes involved critical thinking and reasoning that influenced appropriate responses and execution within a practice domain. Critical thinking behavior in individual- and team-athletes had been established as the process of skillful matter of knowledge and experience in making discriminating judgments and evaluations [24]. Effective problem-solving process was realized in five steps, namely: believing in solving and adapting to problem, defining the problem approximately and deciding achievable targets, forming different alternatives to clear the block, predicting how positive and negative results of alternatives and how maximum efficiency was obtained with the lowest cost, and creating a plan and trying it elite athletes' real lives. It was expected that perception, comprehension, and decision making wee obtainable towards the regular exercise and participation that will positively contribute to the problem-solving strategies [25].

Regarding elite athletes' supports, self-awareness firstly became the ability of understanding elite athletes' strengths and weaknesses as well as recognize their emotion consistency. In sports, self-awarenes was essential for success. By recognizing and accepting their role, an elite athlete performed better in both individual- and team-athletes category. Perceiving elite athletes' emotion consistency in the midst of their day-to-day individual lives and professional competitions would be the hardest thing. Losing control of emotion could affect individual and team performance, as well as team morale and their individual lives. Emotion could be a positive trigger in elite athletes' endeavors, whilst negative emotion could be extremely hurtful to elite athletes' morale. By recognizing elite athletes' emotion consistency, they began to take decisions appropriately. Secondly, elite athletes' support relied on its empathy. In this respect, an elite athlete was not always at the top performance. It was important to understand that this would be better to show empathy to the individual- and team-athletes when they met problems and things that should be fixed. Thirdly, elite athletes complied with the social skills. Acknowledging social skills was one of the most important traits. To gain effective social skills, an elite athlete should be aware of their emotions and be able to regulate those emotions. Social skills were also important to have when elite athletes attempted to convey an idea or persuade the others. Both situations involve strong interpersonal skills and also a complete understanding of elite athletes' daily lives [4], by adhering and observing their mental rehearsal continuity as well that increased the physical performance [26].

Indeed, the results found in this research support elite athletes' determinants to convey good robustness and capacity for generalization, and, to some extent, the results also help to better understand the role of either individual- and team-athletes category towards their selfconfidence, motivation, concentration, and anxiety [27]. Notwithstanding, as to the current discoveries utilizing this model, it was important to repeat that this approach was a correlational research, which meant it did not permit cause-impact connections to be extrapolated, and the results acquired could be deciphered in various manners relying upon the viewpoint of the elite athletes. So, as to be able to explain the existing relationships among the determinants. Future research was recommended to analyze in-depth-results through the longitudinal research which could identify the relationships between individual- and teamathletes more significantly. Furthermore, the influence of self-expression, self-control, and 
problem-solving would be meaningful, based on the fact that the way elite athletes perceived regarding their individual lives in order to take appropriate decisions.

\section{Conclusion}

This research may be of interest to elite athletes since they are suggested to have supports for their own autonomy positively in managing the emotion consistency that involves three determinants of self-expression, self-control, and problem-solving. As for self-expression, self-control, and problem-solving may positively predict autonomous motivation and selfesteem, although self-control shows the lowest result in both individual- and team-elite athletes' emotion consistency when this determinant influence in elite athletes' individual lives. Herein, elite athletes' autonomous motivation and self-esteem accordingly encourage resilience and psychology condition. This research confirmably shows the importance of elite athletes being attentive to the emotions of various situations as they portray an appropriate emotion models in their individual lives, although among these determinants do not specifically show close correlations.

\section{References}

[1] Journal of Physical Education and Sports Management: Bal, BS, Singh, K, Sood, M, \& Kumar, $\mathrm{S}$. Emotional intelligence and sporting performance: a comparison between open- and closed-skill athletes. 2011; 2(5): 48-52.

[2] Annals of Neurosciences: Singh, Y, \& Sharma, R. Relationship between general intelligence, emotional intelligence, stress levels and stress reactivity. 2012; 19(3): 107-111. doi: 10.5214/ans.0972.7531.190304

[3] Psychology of Sport and Exercise: Vink, K, Raudsepp, L, \& Kais, K. Intrinsic motivation and individual deliberate practice are reciprocally related: Evidence from a longitudinal study of adolescent team sport athletes. 2015; 16: 1-6. doi: 10.1016/j.psychsport.2014.08.012

[4] Emotional intelligence: The key to athletic and business success: Staff in Job Search Tips. Retrieved March 26, 2021, from https://www.nexgoal.com/emotional-intelligence-the-key-toathletic-and-business-success/

[5] European Journal of Sports and Exercise Science: Birwatkar, VP. Emotional intelligence: The invisible phenomenon in sports. 2014; 3(3):19-31.

[6] International Journal of Environmental Research and Public Health: Trigueros, R, AguilarParra, JM, Álvarez, JF, González-Bernal, JJ, \& López-Liria, R. Emotion, psychological well-being and their influence on resilience: A study with semi-professional athletes. 2019; 16(4192): 1-12. doi: 10.3390/ijerph16214192

[7] Journal of Human Sport and Exercise: Castro-Sánchez, M, Chacón-Cuberos, R, Zurita-Ortega, F, Puertas-Molero, P, Sánchez-Zafra, M, \& Ramírez-Granizo, I. Emotional intelligence and motivation in athletes of different modalities. 2016; 13(2proc): 162-177. doi: 10.14198/jhse.2018.13.Proc2.01

[8] Sport Medicine: Rice, SM, Purcell, R, De Silva, S, Mawren, D, McGorry, PD, \& Parker, AG. The mental health of elite athletes: a narrative systematic review. 2016; 46(9): 1333-1353. doi: 10.1007/s40279-016-0492-2

[9] Behavioral Sciences: Dal, N. The influence of trait emotional intelligence on archers' autonomic cardiac recovery responses immediately after a shooting session. 2019; 9(55): 1-7. doi: $10.3390 /$ bs 9050055

[10] Universidad Europea de Madrid, Spain: Bekendam, N. Diferencias en inteligencia, inteligencia emocional y personalidad entre nadadores y sujetos sedentarios (Tesis Doctoral). 2013. 
[11] Universidad de Las Palmas de Gran, Canaria, Spain: Pérez, A. Inteligencia emocional y motivación en el estudiante Universitario (Tesis Doctoral). 2012.

[12] Universidad Camilo José, Cela, Spain: Lezcano, R. Influencia de los estilos educativos y las características psicoemocionales en el desarrollo de jóvenes futbolistas de élite (Tesis Doctoral). 2016.

[13] Salud y Drogas: Castro-Sánchez, M., Zurita-Ortega, F., Chacón-Cuberos, R., Martínez-Martínez, A., Espejo-Garcés, T., \& Álvaro-González, J. Sustancias nocivas y clima motivacional en relación a la práctica de actividad física. $2015 ; 15(2)$ : 115-126. doi: 10.21134/haaj.v15i2.244

[14] European Journal of Education and Psychology: Inglés, C, Torregrosa, M, García-Fernández, J, Martínez-Monteagudo, M, Estévez, E, \& Delgado, B. Conducta agresiva e inteligencia emocional en la adolescencia. 2014; 7(1): 29-41. doi: 10.30552/ejep.v7i1.97

[15] Universidad de Málaga, Málaga, Spain: Pineda, C. Inteligencia emocional y bienestar personal en estudiantes universitarios de ciencias de la salud (Tesis Doctoral). 2012.

[16] Universidad de León, León, Spain: Trigoso, M. Inteligencia emocional en jóvenes y adolescentes españoles y peruanos: variables psicológicas y educativas (Tesis Doctoral). 2013.

[17] Universidad de Valencia, Valencia, Spain: Ysern, L. Relación entre la inteligencia emocional, recursos y problemas psicológicos, en la infancia y adolescencia (Tesis doctoral). Universidad de Valencia, Valencia, Spain, 2016.

[18] Global Journal of Human-Social Science: Arts \& Humanities - Psychology: Funatsu, Y. Usage of self-talk in competition by athletes. $2018 ; 18(1): 1-6$.

[19] International Journal of Sports Science \& Coaching: Balk, YA, \& Englert, C. Recovery selfregulation in sport: theory, research, and practice. 2020; 15(2): 273-281. doi: $10.1177 / 1747954119897528$

[20] Kasetsart Journal of Social Sciences: Jae-Ahm, P, Mi-Hyang, P, Ji-Hye, S, Li, B, Rolfe, DT, Yoo, J-Y, \& Dittmore, SW. Effect of sports participation on Internet addiction mediated by self-control: A case of Korean adolescents. 2016; 37(3): 164-169. doi: 10.1016/j.kjss.2016.08.003

[21] Journal of Applied Sport Psychology: Chen, LH, \& Chia-Huei Wu, C-H. Gratitude enhances change in athletes' self-esteem: the moderating role of trust in coach. 2014; 26(3): 349-362. doi: 10.1080/10413200.2014.889255

[22] Frontiers in Psychology: Englert, C. The strength model of self-control in sport and exercise psychology. 2016; 7(314): 1-9. doi: 10.3389/fpsyg.2016.00314

[23] Journal of Applied Sport Psychology: Toering, T, \& Gordet, G. Self-control in professional soccer players. 2015; 00: 1-16. doi: 10.1080/10413200.2015.1010047

[24] Journal of Athletic Training: Gardin, FA, \& Mensch, JM. Diagnostic problem solving in male collegiate athletic trainers. 2014; 49(4): 521-531. doi: 10.4085/1062-6050-49.3.04

[25] Physical Culture and Sport: Studies and Research: Senduran, F, \& Amman, T. Problem-solving skills of high school students exercising regularly in sport teams. 2015; 67: 42-52. doi: $10.1515 /$ pcssr-2015-0021

[26] The 5th International Seminar on Physical Health and Education (ISPHE): Setyawati, H, Sumekto, DR, Haziyanti, N, Suraya, F, Sungkowo, Kusumaningtyas, T, \& Pratama, LP. In: Handayani, O., Sumartiningsih, S., and Putriningtyas, N. Athletes' stress determinants when countering fear of failures at their training center program. Proceedings of the $5^{\text {th }}$ International Seminar of Public Health and Education, ISPHE; July 22, 2020; Semarang State University. Semarang, Indonesia: EUDL (European Union Digital Library); 2020. 238-250. doi: 10.4108/eai.22-7-2020.2300281

[27] The $5^{\text {th }}$ International Conference on Physical Education, Sport, and Health (ACPES 2019): Setyawati, H, Sumekto, DR, Sungkowo, \& Rozi, F. In: Fauzi, L. et al. Identifying factors influencing the martial arts athletes' performance. Proceedings of The $5^{\text {th }}$ International Conference on Physical Education, Sport, and Health (ACPES 2019); September 10-12, 2019; Patrajasa Hotel, Semarang, Indonesia: Atlantis Press; 2019. 59-65. doi: 10.2991/acpes-19.2019.13 